\title{
Synthesis, Structure, and Cytotoxicity of a New Sulphanyl-Bridged Thiadiazolyl-Saccharinate Conjugate: The Relevance of S...N Interaction
}

\author{
Lília I. L. Cabral, ${ }^{[a, b]}$ Elisa M. Brás, ${ }^{[c]}$ Marta S. C. Henriques, ${ }^{[\mathrm{d}]}$ Catia Marques, ${ }^{[b]}$ Luís M. T. Frija, $^{[\mathrm{e}]}$ \\ Luísa Barreira, ${ }^{[a, b]}$ José António Paixão, ${ }^{[d]}$ Rui Fausto, ${ }^{*[c]}$ and Maria Lurdes S. Cristiano* ${ }^{*[a, b]}$
}

Abstract: Reports showing that the copper concentration is considerably higher in neoplasms than in normal tissues prompted the need to develop selective copper chelators. We disclosed recently that some $\mathrm{N}$-linked tetrazole-saccharinates bind selectively to copper, forming complexes that are highly cytotoxic towards cancer cells. Because tetrazole-saccharinates are photolabile, due to the photoreactivity of tetrazoles, we proposed thiadiazolyl-saccharinates as an alternative. Herein we describe the synthesis, structure, and monomeric photochemistry of a sulphanyl-bridged thiadiazolylsaccharinate, 3-[(5-methyl-1,3,4-thiadiazol-2-yl)sulphanyl]-1,2benzothiazole 1,1-dioxide (MTSB). The monomeric structure, charge density analysis, and characteristic infrared spectrum of MTSB were investigated theoretically, using quantum chemical calculations, and also experimentally, using matrixisolation infrared spectroscopy. The crystal structure was in- vestigated by combining X-ray crystallography with infrared and Raman spectroscopies. Results show that the structure of isolated MTSB is similar to that found in the crystal, with an $\mathrm{S} \cdots \mathrm{N}$ interaction clearly contributing to the structure of the molecule and of the crystal. Matrix irradiation revealed a high photostability of MTSB, compared to parent tetrazolesaccharinates and to the 5-methyl-1,3,4-thiadiazole building block, emphasizing the photostabilizing effect of the saccharyl system. Finally, in vitro toxicity assays of MTSB showed a copper concentration-dependent toxicity against cancer cells, without affecting normal cells. In particular, MTSB was most effective towards the hepatic (HepG2), neuroblastoma (SH-SY5), and lymphoma cell lines (U937). Thus, MTSB represents a promising lead for cancer chemotherapy based on chelating agents.

\section{Introduction}

Coordination chemistry is very relevant in crucial areas, such as catalysis, supramolecular chemistry, molecular magnetism, optical materials, environmental remediation and medicine. ${ }^{[1-4]}$ Multidentate ligands may be viewed as the touchstone in co-

[a] L. I. L. Cabral, Prof. L. Barreira, Prof. M. L. S. Cristiano Department of Chemistry and Pharmacy, F.C.T. University of Algarve, 8005-039 Faro (Portugal)

[b] L. I. L. Cabral, C. Marques, Prof. L. Barreira, Prof. M. L. S. Cristiano Center of Marine Sciences, CCMar

University of Algarve, 8005-039 Faro (Portugal) E-mail:mcristi@ualg.pt

[c] E. M. Brás, Prof. R. Fausto

CQC, Department of Chemistry

University of Coimbra, 3004-535 Coimbra (Portugal)

E-mail:rfausto@ci.uc.pt

[d] M. S. C. Henriques, Prof. J. A. Paixão CFisUC, Department of Physics University of Coimbra, 3004-516 Coimbra (Portugal)

[e] Dr. L. M. T. Frija CQE, Centro de Química Estrutural, IST University of Lisbon, Av. Rovisco Pais, 1049-001 Lisbon (Portugal)

$\square$ Supporting information and the ORCID identification number(s) for the au-

(iD thor(s) of this article can be found under https://doi.org/10.1002/ chem.201705319. ordination chemistry because their structure and chemical nature determines the reactivity and function of coordination structures. In designing ligands, the binding affinity and selectivity towards a specific metal are instrumental features to consider, especially if applications in medicinal chemistry are envisaged, for which structure-based design must keep in pace with the increasing demand for solutions that provide higher effica$c y$, while reducing toxicity.

The design of selective ligands for copper has attracted attention is recent years. This metal is involved in a variety of vital redox processes in the human body and alterations of its normal homeostasis are known to promote toxicity through induced formation of reactive oxygen species (ROS) that may target lipids, proteins, or nucleic acids..$^{[5-7]}$

It has been reported that the proliferation of cancer cells requires a higher abundance of $\mathrm{Cu}^{\prime \prime}$ than that of corresponding normal cells. ${ }^{[8,9]}$ Additionally, it was proposed that the apoptotic properties of Elesclomol, a drug candidate currently under clinical evaluation for cancer chemotherapy, arise from its coordination to copper(II), leading to a complex that promotes formation of ROS in cancer cells. ${ }^{[10]}$ This evidence prompted the development of new copper chelators that can avidly capture copper ions in neoplasms, depriving them of $\mathrm{Cu}^{\prime \prime}$. If, in addition, the redox-active copper complexes generate harmful re- 
active oxygen species (ROS) in cancer cells, then the copper chelators could inhibit tumor growth by a dual-mode of action, behaving as powerful tools for cancer chemotherapy. In view of these potential applications, the mandatory properties of such copper chelators include negligible cytotoxicity, high binding affinity and selectivity towards $\mathrm{Cu}^{\prime \prime}$, in addition to chemical stability, drug-like properties, and easy access through chemical synthesis.

Saccharin (3-oxo-1,2-benzisothiazole 1,1-dioxide) ${ }_{1}^{[1]}$ the oldest artificial sweetener known, and related saccharinates (known as benzisothiazoles), are generally stable and non-toxic compounds and are also known to act as bridging ligands in coordination chemistry. ${ }^{[3,12]}$ Additionally, the saccharyl system is easily linked to other heterocycles by using 3-chloro-1,2-benzisothiazole 1,1-dioxide (2; Scheme 1$)$ as the saccharyl building block, providing easy access to a plethora of saccharinatebased conjugates that can be screened as multidentate ligands.

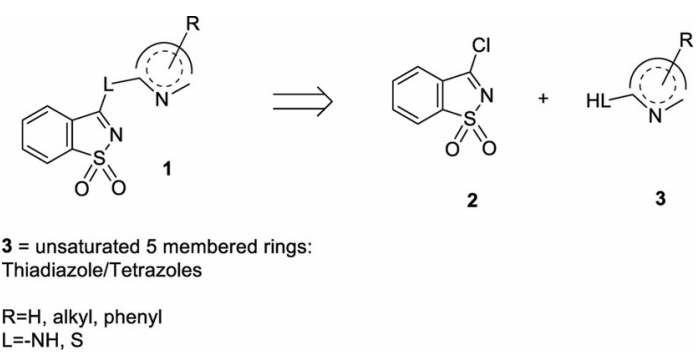

Scheme 1. Proposed retrosynthetic strategy to saccharin-based conjugates 1.

We recently developed saccharinate-based molecules where the saccharyl system is linked to a tetrazolyl moiety (1; Scheme $1 ; R=$ tetrazolyl), studied their structure and proper$\operatorname{ties}^{[13-15]}$ and uncovered their potential as multidentate nitrogen ligands in coordination chemistry. Interestingly, it was found that some of the $\mathrm{N}$-linked tetrazole-saccharinates investigated act readily as selective $\mathrm{Cu}^{\text {"l }}$ chelators, over Fe" and Ca". ${ }^{\text {[16] }}$ The chelators and corresponding copper complexes were scrutinized regarding their toxicity towards various cancer cell lines and also towards non-tumoral cells. Quite surprisingly, the ligands did not show toxicity but the corresponding copper complexes revealed high toxicity towards all tumor cell lines tested, with $\mathrm{IC}_{50}$ values at the low micromolar range of concentrations. ${ }^{[16]}$ From these preliminary results we selected one compound, 2-methyltetrazole saccharinate, for deeper investigations of anti-proliferative activity, analysis of cell cycle distribution, apoptosis induction, and oxidative stress levels.

Because tetrazoles are known to be photolabile (unlike saccharins, known to be relatively photostable $)^{[17,18]}$ we proposed to develop saccharinate-based conjugates incorporating other heterocycles (Scheme 1) and, considering the properties of thiadiazoles, ${ }^{[19]}$ thiadiazolyl saccharinates appeared to be good candidates.

Herein we describe the synthesis, structure, and monomeric photochemistry of 3-[(5-methyl-1,3,4-thiadiazol-2-yl)sulfanyl]1,2-benzothiazole 1,1-dioxide (MTSB), a sulphanyl-bridged thia- diazolyl-saccharinate. The monomeric structure, charge density analysis, and infrared spectroscopy characteristics of MTSB were investigated theoretically, using quantum chemical calculations, and also experimentally, using matrix-isolation infrared spectroscopy. The crystal structure was investigated by combining X-ray crystallography with infrared and Raman spectroscopies. The photostability of matrix-isolated MTSB was evaluated. Finally, its toxicity was assessed in vitro, towards a range of cancer cell lines and non-tumoral cells.

\section{Results and Discussion}

\section{Synthesis of MTSB}

For a convergent synthesis of MTSB, the saccharyl (2) and thiadiazole (4) building blocks were coupled through nucleophilic displacement of the chloride anion from 2 by the thiol functionality of $\mathbf{4}$ (Scheme 2). The reaction proceeded smoothly, affording the crystalline product in $60 \%$ yield. 3-Chloro-1,2-benzisothiazole 1,1-dioxide (2) was prepared by halogenation of saccharin, as previously described. ${ }^{[17]}$

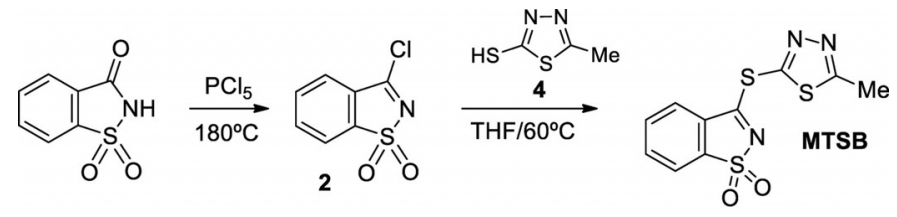

Scheme 2. Synthetic approach to MTSB.

\section{Investigation of the structure of monomeric MTSB}

\section{Quantum chemical calculations for the isolated molecule}

A deep understanding of the structure of MTSB is instrumental for predicting and interpreting its reactivity and properties. As such, monomeric MTSB was investigated theoretically, to determine its preferred conformation. The structures were calculated using Gaussian $09_{1}^{[20]}$ at the DFT level of theory, with the B3LYP hybrid functional ${ }^{[21,22]}$ and the $6-311++\mathrm{G}(\mathrm{d}, \mathrm{p})$ and 6$311++\mathrm{G}(3 \mathrm{df}, 3 \mathrm{pd})$ basis sets. ${ }^{[23,24]}$ In searching for the relevant minima of the isolated molecule of the compound, the potential energy profile for internal rotation about the $S_{12}-C_{13}$ bond (Figure 1) was calculated using the smaller basis set. The more extended basis set was then used to confirm the nature of the initially identified minima and for calculation of the geometrical parameters and vibrational spectra, as well as for undertaking the charge density analysis. The latter was performed according to the theory of Atoms in Molecules (AIM) ${ }^{[25]}$ and the Wiberg bond order analysis, ${ }^{[26,27]}$ using the Multiwfn program (version 3.2). ${ }^{[28]}$

\section{Conformational search and geometry of the minimum energy conformation of MTSB}

The preliminary conformational search was undertaken at the B3LYP/6-311 + + G(d,p) level of approximation. Structures with 


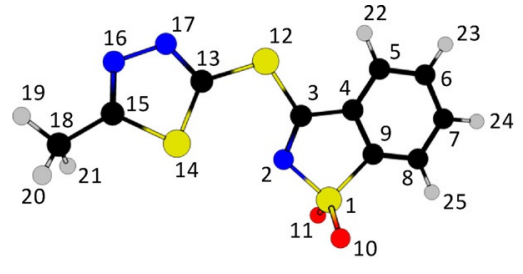

I

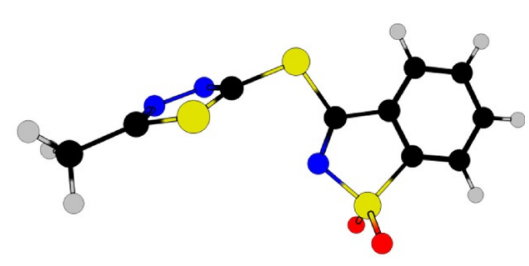

II

Figure 1. (left) Global minimum on the studied potential energy surfaces of MTSB, I. (right) Higher energy minimum (note that a structure symmetricallyequivalent to the one represented in the Figure exists; see text), as predicted by the calculations performed with the smaller $6-311++\mathrm{G}(\mathrm{d}, \mathrm{p})$ basis set; II collapses to the global minimum I upon optimization with the larger $6-311++\mathrm{G}(3 \mathrm{df}, 3 \mathrm{pd})$ basis set.

the $\mathrm{N}_{2}-\mathrm{C}_{3}-\mathrm{S}_{12}-\mathrm{C}_{13}$ fragment in the trans conformation were not taken into account because they are highly sterically hampered due to the close proximity of the two ring moieties (thiadiazole and benzothiazole). The calculated potential energy profile for internal rotation about the $\mathrm{S}_{12}-\mathrm{C}_{13}$ bond, shown in Figure 2, shows 3 minima: a global minimum (I) for

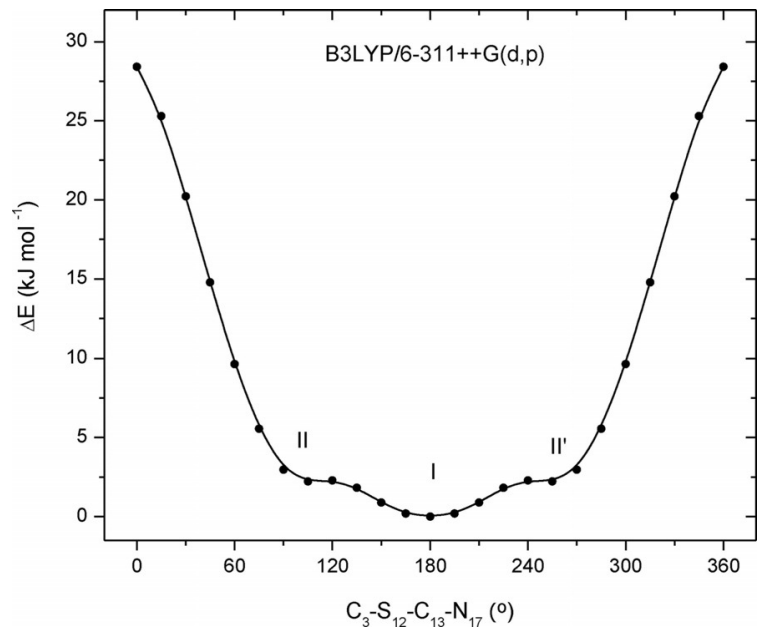

Figure 2. B3LYP/6-311 $++G(d, p)$ calculated potential energy profile for in ternal rotation about the $S_{12}-C_{13}$ bond for MTSB. When reoptimized using the larger $6-311++\mathrm{G}(3 \mathrm{df}, 3 \mathrm{pd})$ basis set, the higher energy minima (II, II') collapse to the minimum energy conformer (I).

$\mathrm{C}_{3}-\mathrm{S}_{12}-\mathrm{C}_{13}-\mathrm{N}_{17}$ equal to $180^{\circ}$ and two symmetry-related higher energy minima (II, II') for $\mathrm{C}_{3}-\mathrm{S}_{12}-\mathrm{C}_{13}-\mathrm{N}_{17}$ equal to $112.3^{\circ}$ (and $247.7^{\circ}$ ) (Figure 1, Figure 2). The higher energy minima stay $2.33 \mathrm{~kJ} \mathrm{~mol}^{-1}$ above the conformational ground state, and are predicted to be separated from this by a very small energy barrier $\left(0.09 \mathrm{~kJ} \mathrm{~mol}^{-1}\right)$. The calculated barrier separating the two symmetrically equivalent minima amounts to $26.24 \mathrm{~kJ} \mathrm{~mol}^{-1}$, the transition state structure corresponding to a $\mathrm{C}_{3}-\mathrm{S}_{12}-\mathrm{C}_{13}-\mathrm{N}_{17}$ dihedral angle of $0^{\circ}$.

The very small energy barrier separating II/II' from the global minimum (I) appeared to be not realistic and further calculations were performed using the larger 6-311++ $\mathrm{G}(3 \mathrm{df}, 3 \mathrm{pd})$ basis set. Indeed, when re-optimized with the more extended basis set, the higher energy minima collapse to the global minimum.

The calculated geometrical parameters for I are provided in Table S1 (in the Supporting Information). The most relevant structural feature of the minimum energy conformation of MTSB is the close proximity of the $S_{14}$ and $N_{2}$ atoms, because the $\mathrm{S}_{14} \cdots \mathrm{N}_{2}$ distance is only $2.896 \AA$, which is considerably shorter than the sum of the van der Walls radii of $N$ and $S(N$ : $1.55 \AA$, S: $1.80 \AA ; \mathrm{N}+\mathrm{S}=3.35 \AA$ ).

The structural relevance of $\mathrm{S} \cdot \mathrm{N} \mathrm{N}$ contacts has been reported long ago by Fausto, Teixeira-Dias and Carey ${ }^{[29]}$ in a study on $\mathrm{N}$ formylglycine dithio acid, in which a 5-membered ring involving an $\mathrm{S}$... N contact also exists in the most stable conformer of the compound. For this compound, the calculated S $\cdots \mathrm{N}$ distance was found to be $2.898 \AA$, in good agreement with the Xray data for the distance between the corresponding atoms in a series of crystalline $\mathrm{N}$-acylglycine dithio esters used as models for enzyme-substrate complexes of cysteine proteas-

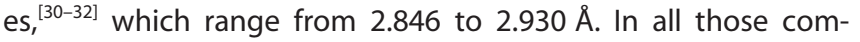
pounds, as in MTSB, the $\mathrm{N}$ atom points to the $\mathrm{S}-\mathrm{R}(\mathrm{R}=\mathrm{H}$ or $\mathrm{C})$ moiety, with the N...S-R angle being larger than $154.4^{\circ}\left(163.5^{\circ}\right.$ for MTSB), thus matching the criterion of Rosenfield et al. ${ }^{[33]}$ for a nucleophilic nitrogen approaching an electrophilic sulphur. According to the literature, ${ }^{[29,31,34]}$ the $\mathrm{S}$...N contact is mainly a $\sigma$-hole chalcogen-type interaction (see Figure S1 in the Supporting Information) involving nitrogen and sulphur orbitals properly oriented spatially. The detailed analysis of the $S_{14} \cdots N_{2}$ interaction in MTSB is presented in the next section, based on both the Atoms in Molecules (AIM) theory ${ }^{[25]}$ and the Wiberg bond order analysis. ${ }^{[26,27]}$

\section{The $S_{14} \cdots N_{2}$ interaction as described by the analysis of the electron charge density (AIM and Wiberg bond order analy- ses)}

Analyses of the charge distribution in the MTSB molecule and of the topological properties of the electron density and the Laplacian of the electron density allowed us to understand some of the fundamental structural characteristics of the molecule, in particular the impact of the $\mathrm{S}_{14} \cdots \mathrm{N}_{2}$ contact on the structure.

A simple and elegant way to estimate the relative strengths of the different bonds in a molecule is to use the AIM theory approach $^{[25]}$ and evaluate the value of the charge density at the bond critical points of the molecule, then correlating these values with the bond strengths. In AIM topology analysis language, the points where the gradient norm of a given real space function value is zero (except at infinity) are called critical points (CP). When the electron density function $(\rho)$ is con- 
sidered, besides the critical points where all three eigenvalues of Hessian matrix of the function are negative (which correspond to local maxima and are nearly coincident with the nuclei), there are three other types of critical points: (i) the bond critical points (BCP), associated to two negative eigenvalues of the Hessian matrix (second-order saddle points), and that appear between attractive atom pairs; (ii) the ring critical points (RCP), exhibiting only one negative eigenvalue of Hessian matrix (first-order saddle point) and that appear in the center of a ring; and (iii) the cage critical points (CCP), where none of the eigenvalues of the Hessian matrix of the electron density function are negative (local minimum) and that are located in the center of a cage system.

The values of real space functions at BCP have great physical significance. For example, the value of $\rho$ and the sign of the Laplacian of the electron density $\left(\nabla^{2} \rho\right)$ at a BCP are closely related to bonding strength and bonding type, respectively. ${ }^{[35,36]}$ The maximal gradient path linking BCP and associating two local maxima of density is termed as "bond path", which reveals the atomic interaction path for all kinds of bonding. The collection of bond paths is known as molecular graph, which provides an unambiguous definition of the molecular structure. ${ }^{[25]}$

Figure 3 shows the molecular graph for MTSB, where the BCP and RCP are shown, together with the bond paths. The values of the electron density function $(\rho)$ and of the Laplacian of the electron density $\left(\nabla^{2} \rho\right)$ at the BCP and RCP are provided in Table 1, together with the calculated bond lengths and Wiberg bond orders. ${ }^{[26,27]}$

Figure 4 presents plots that relate the bond lengths, the bond orders calculated according to the Wiberg's method, ${ }^{[26,27]}$ and the values of the electron density at the associated BCP. Figure 5 shows the contour map of the molecular charge density $(\rho)$ in the molecular plane of MTSB, together with the trajectories of the corresponding gradients, including those delimiting the basins associated with the different atoms. Atomic

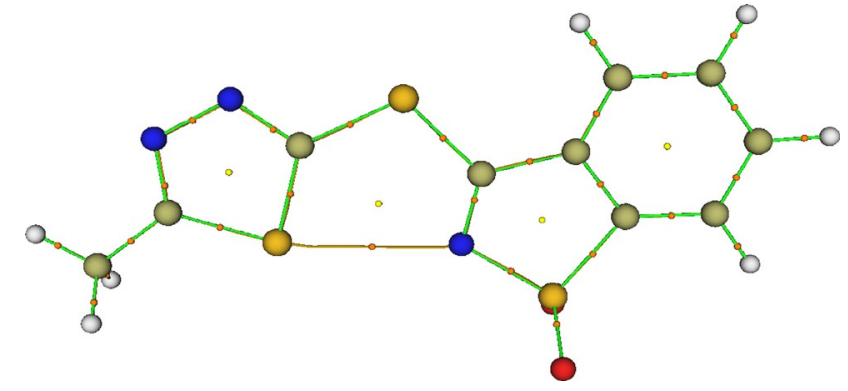

Figure 3. Molecular graph for MTSB, built from the $6-311++\mathrm{G}(3 \mathrm{df}, 3 \mathrm{pd}) \mathrm{cal}-$ culated electron density, showing the positions of the CPs (BCP shown in orange; RCP in yellow) and the bond paths, including those relative to the $\mathrm{S}_{14} \cdots \mathrm{N}_{2}$ contact, whose bond paths are highlighted in orange. Note also the existence of a RCP associated with the $S_{12}-C_{13}-S_{14} \cdots N_{2}-C_{3}$ fragment.

AIM charges (obtained by integration of the charge density within a given basin) are shown in Table 2 .

The most relevant result presented in Figure 3, Figure 5and Table 1 is the presence of a BCP between $\mathrm{S}_{14}$ and $\mathrm{N}_{2}$, which is a clear indication of existence of an attractive interaction between these two atoms. Also significant is the location of a RCP defining the $\mathrm{S}_{12}-\mathrm{C}_{13}-\mathrm{S}_{14} \cdots \mathrm{N}_{2}-\mathrm{C}_{3}$ quasi-ring, which does also stress the attractive character of the $S_{14} \cdots N_{2}$ contact.

The value of the electron density at a $\mathrm{BCP}$ correlates with the strength of the bond or attractive interaction between atoms, and this is clearly seen in Figure 4 (mid and bottom panels), which show plots of $\rho$ (BCP) vs. the atom distances and Wiberg bond-orders. Interestingly, the value of $\rho$ at the BCP associated with the $S_{14} \cdots N_{2}$ contact obeys the general trends exhibited by the values related with the BCP defining the covalent bond in the molecule, following the tendency previously described by Espinosa et al., ${ }^{[36]}$ who noticed that there are no discontinuities in the description of this type of correlation when both strong shared-shell (SS) and weak closeshell (CS) interactions are considered. Also, the value of $\rho$ at

Table 1. Values of the electron density function $(\rho)$ and of the Laplacian of the electron density $\left(\nabla^{2} \rho\right)$ at the BCP and RCP, calculated equilibrium bond distances and Wiberg bond orders. ${ }^{[a]}$

\begin{tabular}{|c|c|c|c|c|c|c|c|c|c|}
\hline Pair of atoms & Bond $\rho$ order & $\nabla^{2} \rho$ & Distance & Bond order & Pair of atoms & $\rho$ & $\nabla^{2} \rho$ & Distance & \\
\hline $\mathrm{C}_{18}-\mathrm{H}_{19}$ & 0.277 & -0.932 & 1.087 & 0.91 & $\mathrm{C}_{5}-\mathrm{H}_{22}$ & 0.283 & -0.982 & 1.081 & 0.86 \\
\hline $\mathrm{C}_{18}-\mathrm{H}_{20}$ & 0.274 & -0.910 & 1.090 & 0.91 & $\mathrm{C}_{5}-\mathrm{C}_{4}$ & 0.308 & -0.853 & 1.388 & 1.39 \\
\hline $\mathrm{C}_{18}-\mathrm{H}_{21}$ & 0.274 & -0.910 & 1.090 & 0.91 & $\mathrm{C}_{9}-\mathrm{S}_{1}$ & 0.200 & -0.367 & 1.785 & 0.83 \\
\hline$C_{15}-C_{18}$ & 0.255 & -0.617 & 1.491 & 1.11 & $\mathrm{C}_{4}-\mathrm{C}_{9}$ & 0.312 & -0.862 & 1.388 & 1.36 \\
\hline $\mathrm{N}_{16}-\mathrm{C}_{15}$ & 0.369 & -1.003 & 1.300 & 1.88 & $\mathrm{C}_{5}-\mathrm{C}_{6}$ & 0.308 & -0.855 & 1.392 & 1.46 \\
\hline $\mathrm{N}_{16}-\mathrm{N}_{17}$ & 0.354 & -0.654 & 1.361 & 1.49 & $\mathrm{C}_{8}-\mathrm{C}_{9}$ & 0.311 & -0.870 & 1.379 & 1.45 \\
\hline $\mathrm{S}_{14}-\mathrm{C}_{15}$ & 0.202 & -0.348 & 1.742 & 1.32 & $\mathrm{C}_{6}-\mathrm{H}_{23}$ & 0.284 & -0.985 & 1.081 & 0.88 \\
\hline $\mathrm{C}_{13}-\mathrm{N}_{17}$ & 0.373 & -1.055 & 1.299 & 1.91 & $\mathrm{C}_{6}-\mathrm{C}_{7}$ & 0.308 & -0.859 & 1.393 & 1.46 \\
\hline $\mathrm{S}_{14}-\mathrm{C}_{13}$ & 0.200 & -0.343 & 1.736 & 1.31 & $\mathrm{C}_{7}-\mathrm{C}_{8}$ & 0.306 & -0.848 & 1.394 & 1.45 \\
\hline $\mathrm{S}_{12}-\mathrm{C}_{13}$ & 0.193 & -0.337 & 1.760 & 1.23 & $\mathrm{C}_{8}-\mathrm{H}_{25}$ & 0.284 & -0.991 & 1.080 & 0.87 \\
\hline $\mathrm{C}_{3}-\mathrm{S}_{12}$ & 0.202 & -0.375 & 1.739 & 1.32 & $\mathrm{C}_{7}-\mathrm{H}_{24}$ & 0.284 & -0.985 & 1.081 & 0.88 \\
\hline $\mathrm{C}_{3}-\mathrm{N}_{2}$ & 0.376 & -0.965 & 1.283 & 1.96 & $\mathrm{~S}_{14} \cdots \mathrm{N}_{2}$ & 0.017 & 0.054 & 2.868 & 0.15 \\
\hline $\mathrm{S}_{1}-\mathrm{N}_{2}$ & 0.214 & -0.469 & 1.692 & 0.97 & $\mathrm{R}_{\text {Thiadiazole }}$ & 0.043 & 0.291 & & \\
\hline$C_{3}-C_{4}$ & 0.260 & -0.619 & 1.487 & 1.04 & $\mathrm{R}_{\text {Thiazole }}$ & 0.038 & 0.236 & & \\
\hline $\mathrm{O}_{10}-\mathrm{S}_{1}$ & 0.293 & 0.969 & 1.433 & 1.89 & $\mathrm{R}_{\text {Phenyl }}$ & 0.022 & 0.162 & & \\
\hline $\mathrm{O}_{11}-\mathrm{S}_{1}$ & 0.293 & 0.969 & 1.433 & 1.89 & $\mathrm{R}_{\mathrm{S}_{12} \mathrm{C}_{13} \mathrm{~S}_{14} \cdots \mathrm{N}_{2} \mathrm{C}_{3}}$ & 0.012 & 0.054 & & \\
\hline
\end{tabular}



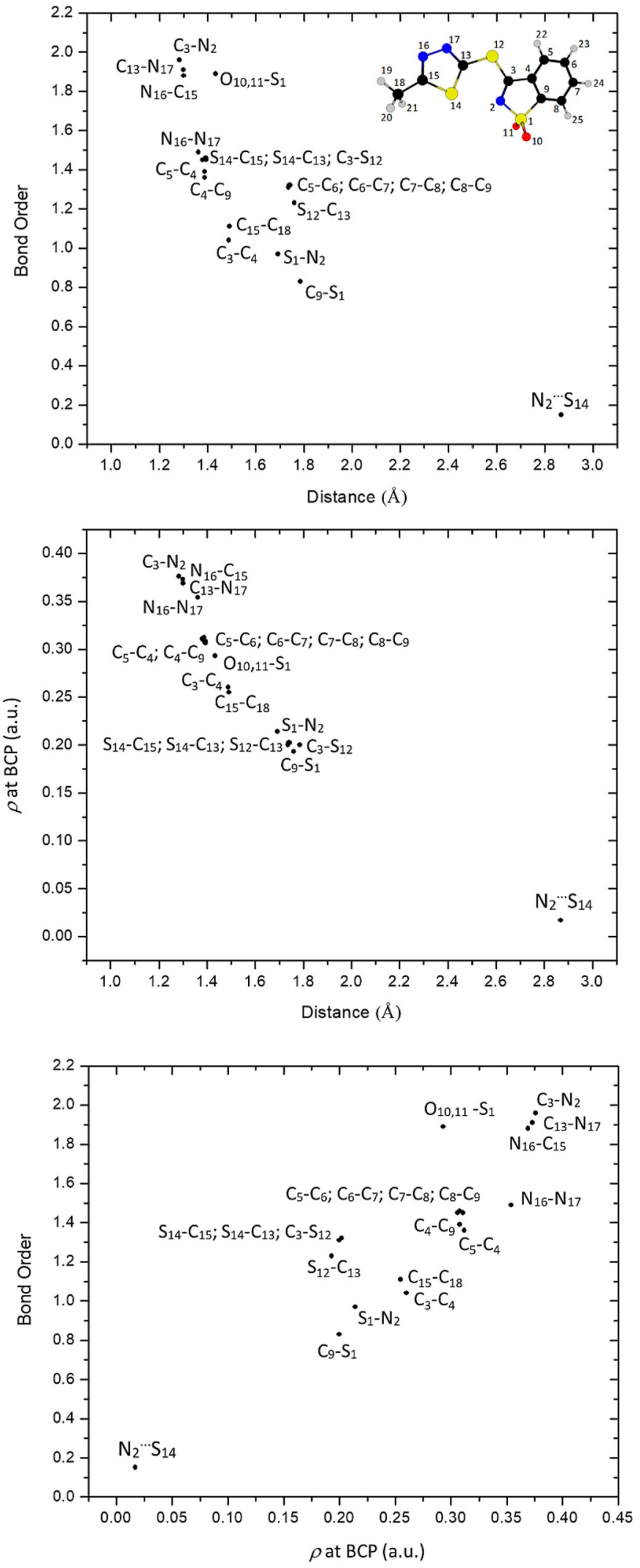

Figure 4. Plots showing the correlations between atomic distances, Wiberg bond orders, and the values of the electron density at the associated BCP.

the $\mathrm{BCP}$ associated with the $\mathrm{S}_{14} \cdots \mathrm{N}_{2}$ contact is similar to those found for a BCP associated to an $\mathrm{H}$-bond in $\mathrm{H}$-bonded sys-

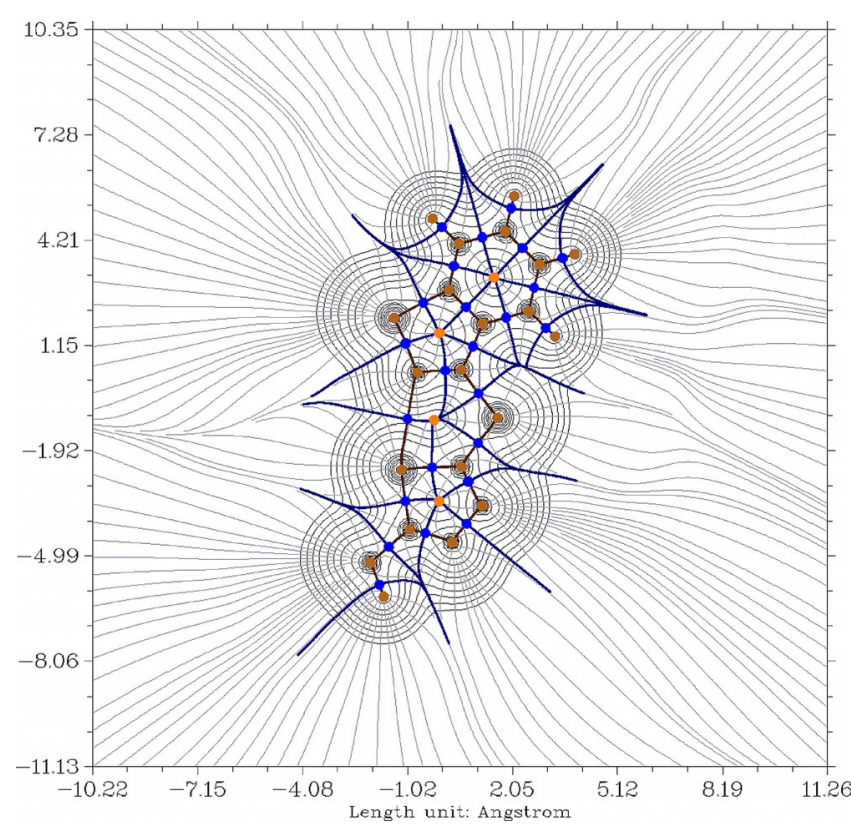

Figure 5. Contour map of the molecular charge density $(\rho)$ in the molecular plane of MTSB, and the trajectories of the corresponding gradients. Atoms are indicated by the dark orange circles; the points marked with the blue and orange circles correspond to BCP and RCP. The two unique gradient paths which originate at infinity or at a ring critical point and terminate at a bond critical point define the boundary between a pair of bonded atoms, in the considered plane. Contour values (in atomic units) in this Figure are $2 \times 10^{n}, 4 \times 10^{n}$ and $8 \times 10^{n}$, where $n$ starts at -3 and increases in steps of unity.

Table 2. AIM atomic charges for isolated MTSB molecule obtained from the theoretical calculations, and multipole and integration atomic charges obtained from the experimentally determined electron densities for crystalline MTSB. ${ }^{\text {[a] }}$

$\begin{array}{cl}\text { Atomic charge } & \text { Atomic charge } \\ \text { Atom AIM Multipole Integration Atom AIM Multipole Integration }\end{array}$

$\begin{array}{llllllll}\mathrm{S}_{1} & 2.671 & 0.74(5) & 0.237 & \mathrm{~S}_{14} & 0.521 & 0.34(4) & 0.068\end{array}$

$\begin{array}{llllllll}\mathrm{N}_{2} & -1.084 & -0.19(6) & -0.16 & \mathrm{C}_{15} & 0.424 & -0.16(6) & 0.03\end{array}$

$\begin{array}{llllllll}\mathrm{C}_{3} & 0.534 & -0.21(6) & 0.05 & \mathrm{~N}_{16} & -0.625 & -0.10(6) & -0.09\end{array}$

$\begin{array}{llllllll}C_{4} & -0.038 & -0.04(5) & -0.02 & N_{17} & -0.601 & -0.06(6) & -0.06\end{array}$

$\begin{array}{llllllll}\mathrm{C}_{5} & 0.023 & 0.02(6) & 0.02 & \mathrm{C}_{18} & -0.008 & 0.03(8) & 0.04\end{array}$

$\begin{array}{llllllll}\mathrm{C}_{6} & -0.003 & -0.04(7) & 0.03 & \mathrm{H}_{19} & 0.079 & 0.07(4) & 0.05\end{array}$

$\begin{array}{llllllll}\mathrm{C}_{7} & -0.012 & 0.06(6) & -0.01 & \mathrm{H}_{20} & 0.042 & 0.07(4) & 0.06\end{array}$

$\begin{array}{llllllll}\mathrm{C}_{8} & 0.039 & -0.08(7) & -0.03 & \mathrm{H}_{21} & 0.042 & 0.07(4) & 0.06\end{array}$

$\begin{array}{llllllll}\mathrm{C}_{9} & -0.097 & -0.17(6) & -0.06 & \mathrm{H}_{22} & 0.062 & 0.08(8) & 0.02\end{array}$

$\begin{array}{llllllll}\mathrm{O}_{10} & -1.224 & -0.44(3) & -0.31 & \mathrm{H}_{23} & 0.066 & 0.08(8) & 0.09\end{array}$

$\begin{array}{llllllll}\mathrm{O}_{11} & -1.224 & -0.44(3) & -0.30 & \mathrm{H}_{24} & 0.056 & 0.17(7) & 0.13\end{array}$

$\begin{array}{llllllll}\mathrm{S}_{12} & 0.421 & 0.24(4) & 0.057 & \mathrm{H}_{25} & 0.071 & 0.16(8) & 0.13\end{array}$

$\begin{array}{llll}\mathrm{C}_{13} & 0.314 & -0.20(6) & -0.03\end{array}$

[a] Charges are in atomic units (units of $e$ ). The MTSB molecules in the studied crystal of the compound have a non-planar skeleton, so that the pairs of atoms $\mathrm{O}_{10} / \mathrm{O}_{11}$ and $\mathrm{H}_{20} / \mathrm{H}_{21}$ are not symmetrically related.

tems, ${ }^{[37]}$ a result that also stresses the structural relevance of the $\mathrm{S}_{14} \cdots \mathrm{N}_{2}$ interaction in the studied molecule.

The values of $\nabla^{2} \rho$ at the BCP can be correlated with the type of bonding: strong shared-shell (SS) covalent interactions are generally characterized by a considerable charge concentration near the BCP and the Laplacian of the electron density 
function at the critical point is negative; conversely, for weak closed-shell (CS) interactions a situation of charge depletion at the BCP occurs, and the Laplacian is positive. ${ }^{[36,37]}$ For SS covalent bonds, values of $\rho$ (in atomic units) of about 0.230 are typical of single bonds while those of ca. 0.340 are typical of double bonds. ${ }^{[38]}$ These trends are clearly evidenced in Table 1, with the Laplacian being positive for the $\mathrm{S}_{14} \cdots \mathrm{N}_{2}$ contact and negative for all covalent bonds, except for the specific case of the $\mathrm{S}=\mathrm{O}$ bonds, for which the Laplacian at the $\mathrm{BCP}$ is positive. Although, as expected, for the $\mathrm{S}=\mathrm{O}$ bonds the electron density at the BCP is large, the fact that the Laplacian is positive indicates that the charge is concentrated in the separate atomic basins rather than in the inter-nuclear region. Such type of interaction has been termed "intermediate" between a sharedand a closed-shell interaction. ${ }^{[37]}$ In an "intermediate"-type interaction, the BCP is located close to the nodal surface of the Laplacian and, consequently, the bonded maximum in the valence shell charge concentration of sulphur lies within the atomic basin of oxygen. This, in turn, is an indication of the charge transfer from sulphur to oxygen, and the integrated AIM atomic charges of sulphur and oxygen confirm this finding (Table 2). Note, though, that the transfer of charge is not an indication of an ionic interaction, as $\rho$ at the BCP has the value of a shared interaction (see Table 1), but rather reflects the polarity of the bond. Similar trends have been reported before for the SO linkage in sulphinylamines and sulphinylhydrazines. ${ }^{[39]}$

The characterization of the RCP in terms of their $\rho, \nabla^{2} \rho$, and integrated total energy density values provides information on the level of electron delocalization of each of the rings in the molecule (thiadiazole, thiazole, and phenyl) and also of the $\mathrm{S}_{12}-\mathrm{C}_{13}-\mathrm{S}_{14} \cdots \mathrm{N}_{2}-\mathrm{C}_{3}$ quasi-ring. The integrated total energy density values for these rings (in atomic units $\times 10^{3}$ ) are, respectively, 7.49, 6.34, 7.54, and 2.47, ordering the rings by increased electron delocalization character as phenyl $\approx$ thiadiazole $>$ thiazole $\gg \mathrm{S}_{12}-\mathrm{C}_{13}-\mathrm{S}_{14} \cdots \mathrm{N}_{2}-\mathrm{C}_{3}$ quasi-ring. These results are in agreement with the expectations: the phenyl and thiadiazole rings are aromatic, whereas the electron delocalization is intermediate in the substituted thiazole ring and negligible in the $\mathrm{S}_{12}-\mathrm{C}_{13}-\mathrm{S}_{14} \cdots \mathrm{N}_{2}-\mathrm{C}_{3}$ quasi-ring. The relative values of both $\rho$ and $\nabla^{2} \rho$ at the RCP accompany the trend of the corresponding energy densities (see Table 1), but in this case the fact that the phenyl ring has a different number of atoms has to be taken into account, since the values of $\rho$ and $\nabla^{2} \rho$ also reflect the extent of steric strain of the ring, increasing with this property. ${ }^{[40]}$ In this regard, the position of the phenyl ring in the series defined based on the values of $\rho$ and $\nabla^{2} \rho$ is affected by the fact that it is considerably less strained. In general, the electron delocalization insights extracted from the AIM topological analysis are in line with the calculated bond-orders for the bonds of the different rings shown in Table 1.

\section{Structure and vibrational spectra of matrix-isolated MTSB monomers}

The infrared spectrum of MTSB isolated in solid argon is presented in Figure 6, in which it can be compared with the simu-
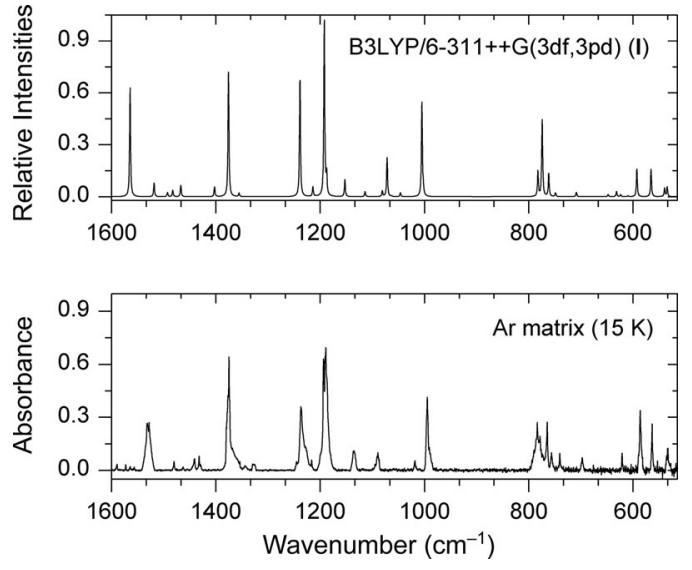

Figure 6. (Top) Simulated IR spectrum built based on the B3LYP/6$311++\mathrm{G}(3 \mathrm{df}, 3 \mathrm{pd})$ calculated data for I. (Bottom) IR spectrum of the as-deposited argon matrix of MTSB (15 K).

lated spectrum generated from the B3LYP/6-311++ G(3df,3pd) calculated data (see also Table S2 in the Supporting Information, with proposed band assignments). In the simulated spectrum, the bands are represented by Lorentzian functions centered at the calculated wavenumbers and with a fullwidth-at-half-maximum of $2 \mathrm{~cm}^{-1}$. No scaling was applied to the wavenumbers. Note that the calculated intensities correspond, in the simulated spectrum, to the areas below the peaks, so that the peak intensities do not correspond to the values shown in Table S2. The chosen theoretical method and basis set have been shown ${ }^{[41]}$ to provide vibrational frequencies in very good agreement with the experimental data (without requiring scaling), in particular for the vibrations of the $-\mathrm{SO}_{2}$ - fragment, usually difficult to describe.

From Figure 6, it can indeed be concluded that the B3LYP/ $6-311++\mathrm{G}(3 \mathrm{df}, 3 \mathrm{pd})$ calculations are able to predict properly the IR spectrum of MTSB. On the other hand, preliminary calculations performed with the smaller $6-311++G(d, p)$ basis set were found to strongly underestimate the frequencies for the modes localized in the $-\mathrm{SO}_{2}$ - fragment, in particular the two stretching vibrations and the scissoring and wagging modes. These results follow the trends described in previous studies ${ }^{[41,42]}$ in which the infrared spectra of other molecules bearing the $-\mathrm{SO}_{2}$ - moiety were discussed. It has been shown that the use of highly polarized basis sets is necessary to provide the wavefunction the required flexibility to account properly for properties (including vibrational frequencies) of hypervalent sulphur containing molecules.

The spectrum of MTSB is dominated by the bands originating predominantly in the $-\mathrm{SO}_{2}$ - fragment and the $\mathrm{C}_{3}-\mathrm{S}_{12}$ bond of the bridging group. The most intense band in the spectrum is observed as a site-split band with maxima at 1193/1190/ $1189 / 1188 \mathrm{~cm}^{-1}$ (calculated $1192 \mathrm{~cm}^{-1}$ ) and is assigned to the $v \mathrm{SO}_{2}$ symmetric stretching. The $\nu \mathrm{SO}_{2}$ anti-symmetric stretching vibration is predicted at $1379 \mathrm{~cm}^{-1}$ and also observed as a multiplet with major maximum at $1374 \mathrm{~cm}^{-1}$, whereas the $\mathrm{SO}_{2}$ scissoring $\left(\mathrm{SSO}_{2}\right)$ and wagging $\left(\mathrm{WSO}_{2}\right)$ modes are predicted at 598 and $566 \mathrm{~cm}^{-1}$, respectively, and observed at 586 and $563 \mathrm{~cm}^{-1}$. According to the calculations, two vibrations pre- 
senting intense IR absorptions have significant contributions from the $C_{3}-S_{12}$ bond stretching of the bridging group. These modes are predicted at $1239 \mathrm{~cm}^{-1}$ (also with a significant contribution from the $v \mathrm{C}_{3}-\mathrm{C}_{4}$ stretching) and $1005 \mathrm{~cm}^{-1}$, and have experimental counterparts with major maxima observed at $1237 / 1236$ and $994 \mathrm{~cm}^{-1}$, respectively.

The features with main maxima observed at 1532/1528 and $779 / 764 \mathrm{~cm}^{-1}$ (with the latter showing a complex band structure spreading within the position of the two main maxima) are assigned to $v \mathrm{C}_{3}=\mathrm{N}_{2}$ and to mixed modes with major contributions from $v \mathrm{C}_{13}-\mathrm{S}_{14}, v \mathrm{~S}_{1}-\mathrm{N}_{2}$, and $v \mathrm{~S}_{1}-\mathrm{C}_{9}$ stretching coordinates, and have been predicted at 1565 and $776 / 774 \mathrm{~cm}^{-1}$, respectively, in good agreement with the experimental values. The complex structure observed in the band at lower frequency is also related to the contribution to this feature originated in another, lower intensity mode predicted to occur in the same spectral region and presenting also major contributions from the $v \mathrm{~S}_{1}-\mathrm{N}_{2}$ and $v \mathrm{~S}_{1}-\mathrm{C}_{9}$ coordinates (see Table $\mathrm{S} 2$ ). The $\nu \mathrm{C}_{13}-\mathrm{S}_{12}$ stretching mode is predicted at $1081 \mathrm{~cm}^{-1}$ and observed at $1090 \mathrm{~cm}^{-1}$. The other, less intense vibrations have also been predicted well by the calculations, including the $v \mathrm{~N}_{16}-\mathrm{N}_{17}$ stretching mode of the thiadiazole ring (calculated: $1114 \mathrm{~cm}^{-1}$; observed $1118 \mathrm{~cm}^{-1}$ ). The global percent error in frequencies for all bands observed experimentally is as low as $2.6 \%$, which clearly demonstrates the general quality of the theoretical predictions and ensures a high degree of confidence to the proposed assignments (see Table S2).

\section{Assessment of the photostability of matrix-isolated MTSB monomers}

The matrix-isolated MTSB was subjected to UV irradiation, performed in situ with broadband UV light produced by a $500 \mathrm{~W}$ $\mathrm{Hg}(\mathrm{Xe})$ lamp set up to provide an output of $200 \mathrm{~W}$ at the sample. During the irradiation experiments, the $\mathrm{Hg}(\mathrm{Xe})$ lamp was fitted with a water filter to absorb heat.

The compound was found to be rather photostable, with only $35-40 \%$ of the initial material being consumed after prolonged $(\approx 3 \mathrm{~h})$ irradiation. The effects of UV irradiation on matrix-isolated 5-methyl-1,3,4-thiadiazole-2-thione (5MTT), the parent compound of the thiadiazole fragment of MTSB, has been studied by Rostkowska et al. ${ }^{[43]}$ Those authors reported observation of tautomerization of the most stable thione tautomeric form to a less stable thiol tautomer of the compound upon irradiation at $\lambda>295 \mathrm{~nm}$. We studied the photochemistry of 5MTT using the same irradiation conditions used for MTSB and noticed that, under these conditions, the compound is promptly photolyzed (consumption was achieved after ca. 30 min of irradiation) to $\mathrm{CS}_{2}$, which was formed together with $\mathrm{N}_{2}$ and ethylene. The increased photostability observed for MTSB, when compared to its 5MTT precursor, then comes in line with recent observations ${ }^{[44]}$ that the benzisothiazole ring bound to other 5-membered heterocycles (e.g., tetrazoles) acts as a photo-stabilizer, at least in conditions of matrix-isolation. Noteworthy also is the observation that the sulphanyl-bridged thiadiazolyl-saccharinate MTSB appears to be considerably more photostable than the tetrazole saccharinates previously investigated. ${ }^{[44]}$

\section{X-ray structure of the crystalline compound}

The molecular structure of MTSB, obtained by single-crystal $\mathrm{XRD}$ at $120 \mathrm{~K}$, is shown in Figure 7 , and determined bond

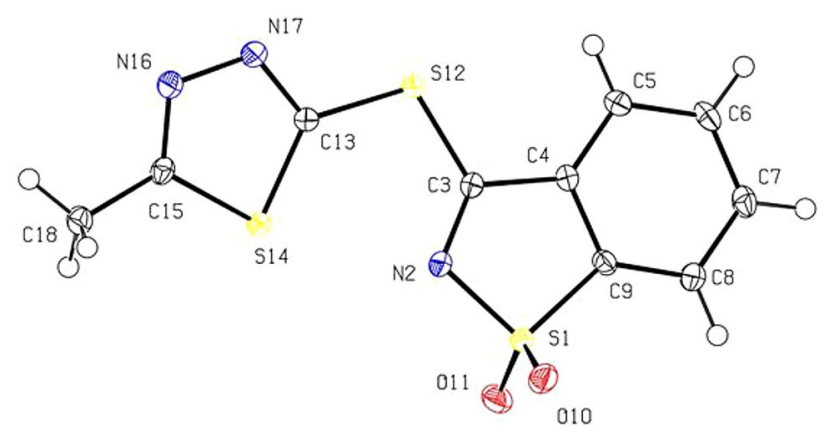

Figure 7. ORTEP drawing of the MTSB molecule showing that anisotropic displacement ellipsoids (drawn at the $50 \%$ probability level) at $120 \mathrm{~K}$.

lengths, valence and dihedral angles are provided in Table S1 in the Supporting Information, in which they can be compared with the geometrical parameters obtained theoretically for the isolated MTSB molecule. As it can be seen in Table S1, the experimentally determined bond lengths and valence angles are in very good agreement with those calculated for the isolated molecule, with the exception of the $\mathrm{S}_{1}=\mathrm{O}_{10}$ bond, which is found to be somewhat longer than the second $\mathrm{S}=\mathrm{O}$ bond $\left(\mathrm{S}_{1}=\right.$ $\mathrm{O}_{11}$ ) and the DFT calculated value. Note that in the isolated molecule these two bonds are equal due to symmetry (the molecule belongs to the $C_{s}$ point group), but in the crystal the symmetry is broken and they become different. Interestingly, as described below in details, the $\mathrm{O}_{10}$ atom is involved in relevant intermolecular interactions (including two $\mathrm{H}$-bond-like interactions of $\mathrm{C}-\mathrm{H} \cdots \mathrm{O}$ type), whereas $\mathrm{O}_{11}$ does not participate in any similar interaction. The intermolecular interactions involving $\mathrm{O}_{10}$ explain the observed elongation of the $\mathrm{S}_{1}=\mathrm{O}_{10}$ bond compared to the $S_{1}=O_{11}$ bond, and the observed deviation in relation to the estimated value for the isolated MTSB molecule.

In the crystal, the 5- and 6-membered rings of the fused benzothiazole group are almost coplanar, the angle between the least-squares plane of the two rings being $1.10(6)^{\circ}$. The thiadiazole 5 -membred ring makes an angle of $9.71(5)^{\circ}$ with the least squares plane of the 9-membered benzothiazole fused rings, showing that the molecule's main skeleton is not planar in the crystalline state. There is, in fact, a rotation of the thiadiazole ring along the $\mathrm{C}_{13}-\mathrm{S}_{12}$ bond, as shown by the torsion angle $\mathrm{S}_{14}-\mathrm{C}_{13}-\mathrm{S}_{12}-\mathrm{C}_{3}$ of $-11.14(8)^{\circ}$.

As found for the isolated molecule, the distance between the $\mathrm{S}_{14}$ and $\mathrm{N}_{2}$ atoms [2.8452(16) $\AA$ ] in the crystal is also significantly shorter than the sum of the atomic van der Walls radii [3.35 $\AA$ ], which indicates that the $\mathrm{S}_{14} \cdots \mathrm{N}_{2}$ interaction is still present in the crystal, in spite of the non-planarity of the molecule.

Packing of the molecules in the crystal appears to be dictated by weak intermolecular interactions of the form $\mathrm{C}-\mathrm{H} \cdots \mathrm{O}, \mathrm{C}-$ 
$\mathrm{H} \cdots \mathrm{N}, \mathrm{S}=\mathrm{O} \cdots \mathrm{C}_{\mathrm{g}}$ and $\mathrm{C}_{\mathrm{g}} \cdots \mathrm{C}_{\mathrm{g}}, \mathrm{C}_{\mathrm{g}}$ being the gravity center of the $\pi$ electron cloud of an aromatic ring, as shown in Table 3 as well as in Figures 8 and 9. Atom $\mathrm{O}_{10}$ acts as a proton acceptor of two $\mathrm{C}-\mathrm{H}$... O weak intermolecular hydrogen bonds and is also involved in one $\mathrm{S}=\mathrm{O} \cdots \mathrm{C}_{\mathrm{g}}$ interaction, whereas atom $\mathrm{O}_{11}$ does

Table 3. Weak intermolecular interactions in the crystal structure of MTSB. ${ }^{[a]}$

\begin{tabular}{|c|c|c|c|c|}
\hline $\mathrm{D}-\mathrm{H} \cdots \mathrm{A}^{[\mathrm{b}]}$ & $\mathrm{D}-\mathrm{H}$ & $\mathrm{H} \cdots \mathrm{A}$ & 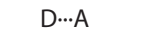 & $\angle D-H \cdots A$ \\
\hline $\mathrm{C}_{7}-\mathrm{H}_{22} \cdots \mathrm{O}_{10}{ }^{i}$ & $1.10(3)$ & $2.55(3)$ & $3.410(2)$ & $134.5(14)$ \\
\hline $\mathrm{C}_{8}-\mathrm{H}_{25} \cdots \mathrm{O}_{10}{ }^{i i}$ & $1.10(4)$ & $2.56(4)$ & $3.591(2)$ & $154.9(14)$ \\
\hline $\mathrm{C}_{18}-\mathrm{H}_{21} \cdots \mathrm{N}_{17}{ }^{i i i}$ & $1.011(18)$ & $2.531(19)$ & $3.510(2)$ & $163.0(14)$ \\
\hline$C_{g}(I) \cdots C_{g}(J)^{[b]}$ & $C_{g}(I) \cdots C_{g}(J)$ & & $C_{\text {gl_perp }}$ & $C_{\text {gJ_perp }}$ \\
\hline$C_{g}(1) \cdots C_{g}(2)^{i v}$ & $4.0605(9)$ & & $3.7518(5)$ & $3.5068(5)$ \\
\hline$C_{g}(2) \cdots C_{g}(3)^{i v}$ & $3.9155(7)$ & & 3.5183(5) & $-6930(5)$ \\
\hline$Y-X \cdots C_{g}$ & $X \cdots C_{g}$ & & $Y \cdots C_{g}$ & $\angle Y-X \cdots C_{g}$ \\
\hline $\mathrm{S}_{1}-\mathrm{O}_{10} \cdots \mathrm{C}_{\mathrm{g}}(2)^{v}$ & $3.8639(17)$ & & $5.2826(8)$ & $160.60(9)$ \\
\hline
\end{tabular}

[a] Distances in $\AA_{;}$angles in degrees. [b] Symmetry codes: $i=x, 3 / 2-y_{\text {, }}$ $-1 / 2+z ; i i=1-x, 1-y_{1}-z ; i i i=-x_{1}-1 / 2+y, 1 / 2-z ; i v=-x, 2-y_{1}-z ; v=$ $1-x_{1}-1 / 2+y_{1} 1 / 2+z . C_{g}(1): S_{1}-N_{2}-C_{3}-C_{4}-C_{9} ; C_{g}(2): S_{14}-C_{13}-N_{17}-N_{16}-C_{15} ;$ $C_{9}(3): C_{4}-C_{5}-C_{6}-C_{7}-C_{8}-C_{9} ; C_{91 \_ \text {perp }}=$ perpendicular distance of $C_{9}(I)$ on ring $J ; C_{g J \_p e r p}=$ perpendicular distance of $C_{g}(J)$ on ring $\mathrm{I}$.

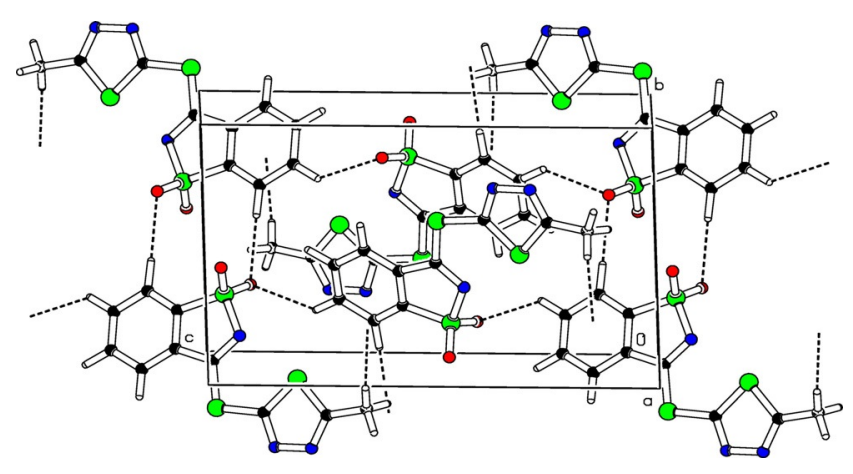

Figure 8. Crystal packing of the MTSB molecules, showing the $\mathrm{C}-\mathrm{H} \cdots \mathrm{O}, \mathrm{C}-$ $\mathrm{H} \cdots \mathrm{N}$ interactions as dashed lines.

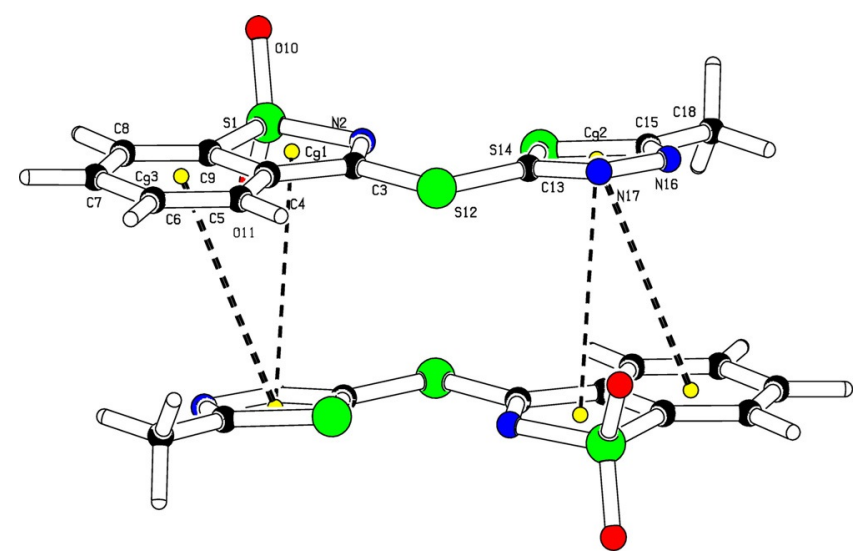

Figure 9. Detail of the interactions (depicted as dashed lines) in the crystal packing between the $\pi$ electron clouds of the aromatic rings. not participate in such interactions. This explains the already noticed asymmetry of the measured $\mathrm{S}=\mathrm{O}$ bond lengths, $\mathrm{S}=\mathrm{O}_{11}$ being longer $[1.4798(19) \AA]$ than $\mathrm{S}=\mathrm{O}_{10}[1.4469(19) \AA]$. Furthermore, this favorable packing asymmetry may also be the cause of the rotation of the thiadiazole ring, along the $C_{13}-S_{12}$ bond, out of the plane of the benzothiazole moiety.

As the XRD data collected at low temperature is of very high quality, the difference electron density map obtained from the observed scattering amplitudes and those calculated using a spherical atom model showed clearly a build-up of positive residual density along the chemical bonds. Thus, we have undertaken another structural refinement using scattering amplitudes from aspherical atoms based on a multipole expansion formalism of the charge density. Technical details of such multipole refinement are given in the Experimental Section. The dynamical deformation density map calculated from the refined multipole model is depicted in Figure 10, where it can be compared with that obtained using the B3LYP/6-311++ $\mathrm{G}(3 \mathrm{fd}, 3 \mathrm{dp})$ calculated data for the isolated molecule. As it can be noticed, the two differential maps show similar patterns, also in the $\mathrm{S}_{14} \cdots \mathrm{N}_{2}$ contact region, where a significant positive residual density between the $\mathrm{S}$ and $\mathrm{N}$ atoms can be clearly observed. Furthermore, the analysis of the critical points of the experimental electron density confirmed the presence of a bond critical point between $\mathrm{S}_{14}$ and $\mathrm{N}_{2}$, as found in the BCP analysis of the DFT density for the isolated molecule. This result confirms the structural relevance of the intramolecular $\mathrm{S}_{14} \cdots \mathrm{N}_{2}$ contact, even in the crystalline phase, where intermolecular packing forces are present. Atomic charges derived from the multipole model (see Table 2) are in qualitative agreement with those derived from the DFT calculations for the isolated molecule, the $\mathrm{S}$ atoms bearing a positive charge, and the $\mathrm{N}$ and $\mathrm{O}$ atoms being negatively charged.

\section{Infrared and Raman spectroscopy of the MTSB crystal}

The infrared (ATR) and Raman spectra of MTSB in the neat crystalline phase are given in Figure 11, together with the simulated spectra built based on the calculated vibrational data for the minimum energy configuration of the isolated MTSB molecule. The proposed assignments are given in Table S2 in the Supporting Information.

The most relevant observation extracted from the data shown in Figure 11is that the calculated spectra (both IR and Raman) for the isolated molecule of MTSB reproduce rather reasonably the experimental spectra of the neat crystal of the compound. This means that the intramolecular vibrational potential is not significantly perturbed by the intermolecular interactions which exist in the crystal. Such conclusion is in agreement with the $\mathrm{X}$-ray structure data that, as pointed out above, revealed weak $\mathrm{C}-\mathrm{H} \cdots \mathrm{O}$ or $\mathrm{C}-\mathrm{H} \cdots \mathrm{N}$ intermolecular contacts as the major interactions present in the crystal. It is also consistent with the relatively low melting point of the compound $\left(190-192^{\circ} \mathrm{C}\right)$, temperature at which the compound also starts to decompose.

Raman temperature variation studies were conducted, from room temperature to $\approx 200^{\circ} \mathrm{C}$. Only minor spectral changes 

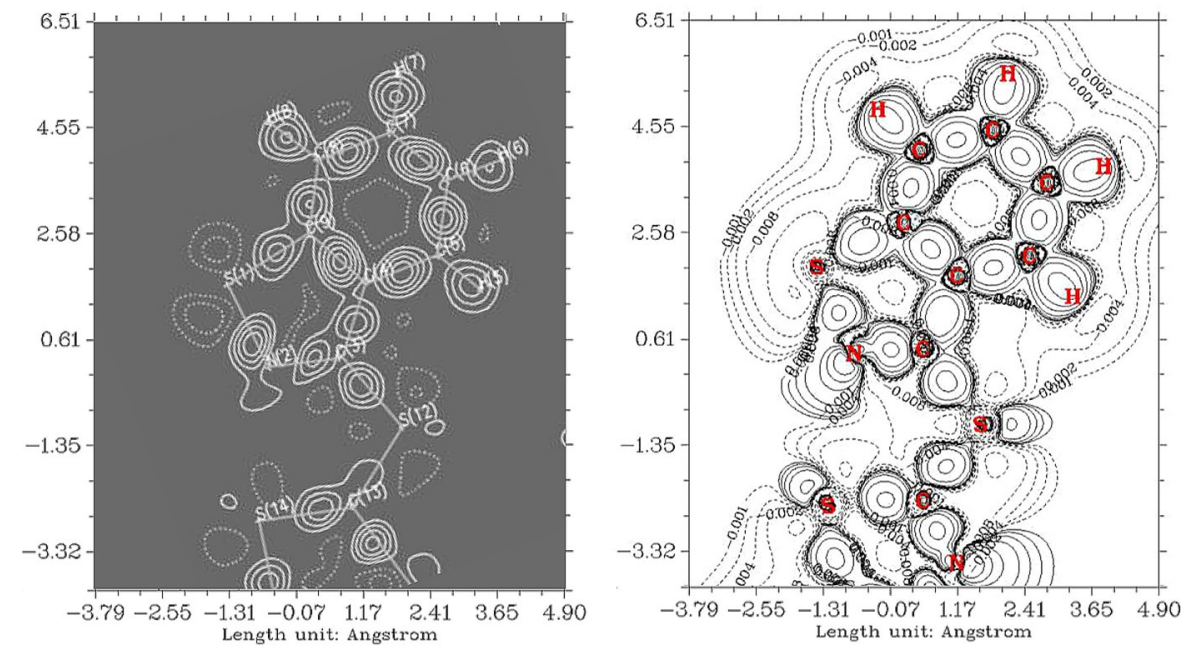

Figure 10. (left) Dynamical deformation density map calculated from the refined multipole model, projected on the $C_{4}-C_{5}-C_{6}$ plane, showing the bonding electron density distribution. (right) B3LYP/6-311+ $+\mathrm{G}(3 \mathrm{fd}, 3 \mathrm{dp})$ calculated data for the isolated molecule (molecular skeleton plane).

were observed (very slight band broadening) before degradation of the compound started, indicating that no phase transitions occur in the whole range of temperatures probed.

We conclude from these findings that the structure of MTSB is similar in the monomeric state and in the crystal state. The structural stability lands predictability when MTSB is considered as bridging ligand in the design of coordination structures.

\section{In vitro cytotoxicity of MTSB}

The cytotoxicity of MTSB was evaluated in vitro against 6 cancer-derived cell lines (HepG2, HeLa, SH-SY5Y, N9, THP-1 and U937) and a non-tumoral cell line (S17). Following previous finding $s^{[6]}$ showing that the physiological concentration of $\mathrm{Cu}^{11}$ in neoplasms range from 30 to around $50 \mu \mathrm{M}$ our experiments were conducted in the presence of $50 \mu \mathrm{M} \mathrm{Cu} u^{\prime \prime}$. The cytotoxicity of MTSB against each cancer cell line, expressed as the half maximal inhibitory concentration $\left(\mathrm{IC}_{50}\right)$, and the corresponding selectivity index, calculated with respect to the non-tumoral cell line (S17), are provided in Table 4.

Table 4. Cytotoxicity of MTSB against the tumor derived cell lines HepG2, HeLa, SH-SY5Y, N9, THP-1 and U937 and the non-tumoral cell line (S17), expressed as $I_{50}[\mu \mathrm{M}]$. The confidence intervals are presented in brackets. The selectivity index (SI) was calculated with reference to the cell line S17.

\begin{tabular}{|lll|} 
& $I_{50}\left(\mathrm{MTSB}+50 \mu \mathrm{M} \mathrm{Cu}^{2+}\right)[\mu \mathrm{M}]$ & $\mathrm{SI}$ \\
\hline S17 & $75.1(72.9-77.4)$ & \\
HepG2 & $16.0(13.6-19.0)$ & 4.68 \\
HeLa & $7.62(6.28-9.25)$ & 9.86 \\
SH-SY5Y & $8.46(7.61-9.40)$ & 8.87 \\
N9 & $33.4(29.7-37.6)$ & 2.25 \\
THP-1 & $119(115-124)$ & 0.63 \\
U937 & $39.9(30.3-52.6)$ & 1.88 \\
\hline
\end{tabular}

Results show that, in the presence of $50 \mu \mathrm{M}$ of $\mathrm{Cu}^{\prime \prime}, \mathrm{MTSB}$ exhibits toxicity towards all cell lines tested, with $I_{50}$ values ranging from ca. 8 to $120 \mu \mathrm{m}$. From the results, MTSB appears to be more toxic (lower $\mathrm{IC}_{50}$ ) to adherent (HepG2, HeLa, SHSY5Y and N9) than to non-adherent (THP-1 and U937) cell lines. For the range of cell lines tested, MTSB exhibited the highest toxicity towards HeLa and SH-SY5Y cells (IC50 of 7.62 and $8.46 \mu \mathrm{M}$, respectively) and also the highest selectivity index (SI of 9.86 and 8.46 , respectively, compared to the S17 cell line).

To understand the dependence of MTSB cytotoxicity on Cu" concentration, another set of experiments were conducted to determine the $\mathrm{IC}_{50}$ for $\mathrm{Cu}$ " towards each cell line, using as fixed concentration of MTSB the $I C_{50}$ value previously determined for the fixed $\mathrm{Cu}^{\prime \prime}$ of $50 \mu \mathrm{M}$ and shown in Table 4. The results obtained for this set of experiments are presented in Table 5.

Results presented in Table 5show that MTSB remains toxic for 5 cell lines, at $\mathrm{Cu}^{\prime \prime}$ concentrations lower than $50 \mu \mathrm{M}$. That was the case for the hepatic line (HepG2; 21.5) and neuroblastoma (SH-SY5Y; 31.4), both adherent cancer cell lines, and for the non-adherent cell lines of monocytic leukemia (THP-1; 45.3) and hystiocytic lymphoma (U937; 26.5). These values fall

Table 5. Cytotoxicity of $\mathrm{Cu}^{\prime \prime}$, expressed as $\mathrm{IC}_{50}[\mu \mathrm{M}]$, towards the cancer derived cell lines HepG2, HeLa, SH-SY5Y, N9, THP-1 and U937 and the non-tumoral cell line S17, in the presence of MTSB at the fixed concentration corresponding to the $\mathrm{IC}_{50}$ values shown in Table 4 . Values in brackets represent the confidence interval.

\begin{tabular}{|lll|} 
& $\mathrm{IC}_{50}\left(\mathrm{Cu}^{2+}\right)[\mu \mathrm{M}]$ & Concentration of MTSB $[\mu \mathrm{M}]$ \\
\hline S17 & $38.5(32.5-45.6)$ & 75.1 \\
HepG2 & $21.5(17.8-25.9)$ & 16.0 \\
HeLa & $75.8(60.9-94.3)$ & 7.62 \\
SH-SY5Y & $31.4(29.8-33.1)$ & 8.46 \\
N9 & $85.3(78.0-93.2)$ & 33.4 \\
THP-1 & $45.3(41.9-48.9)$ & 119 \\
U937 & $26.5(24.2-29.0)$ & 39.9 \\
\hline
\end{tabular}



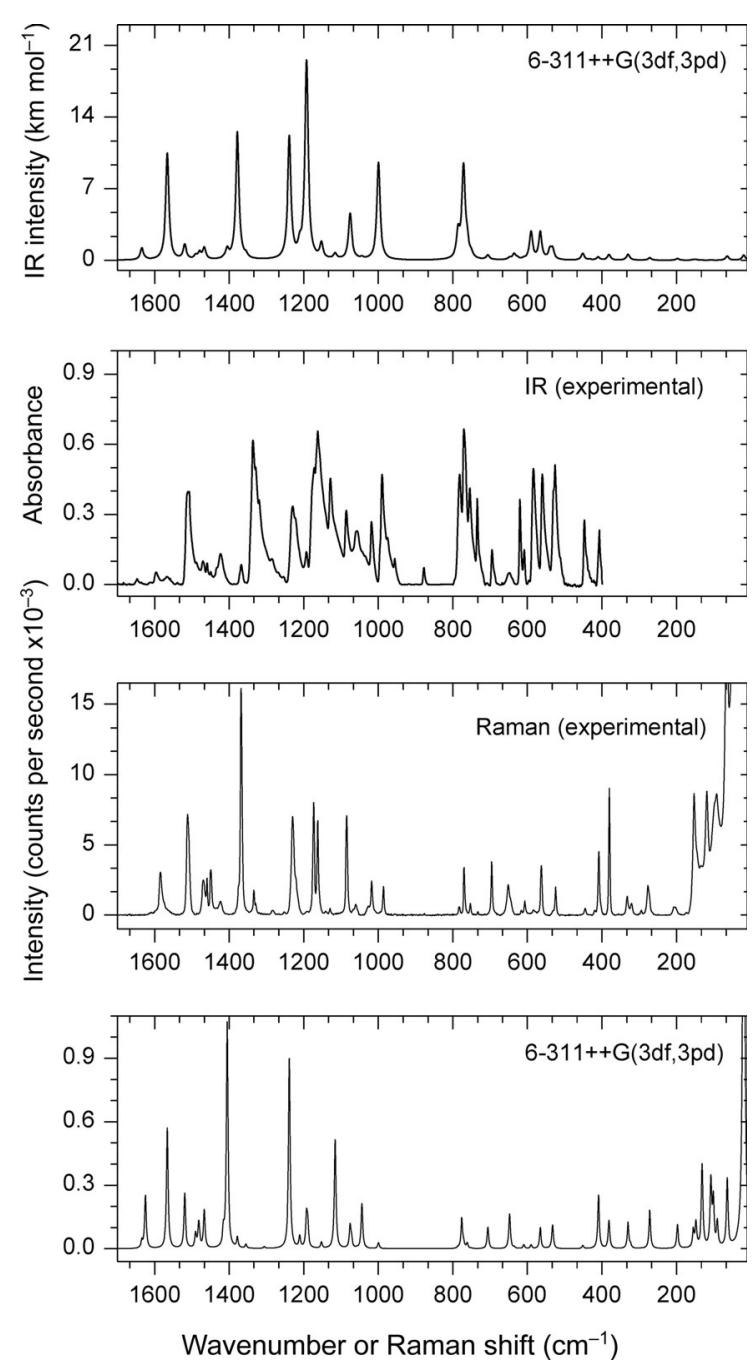

Figure 11. Vibrational spectra for neat crystalline MTSB (room temperature). top and bottom panels: B3LYP/6-311 + $+\mathrm{G}(3 \mathrm{df}, 3 \mathrm{pd})$ calculated infrared and Raman spectra, respectively, for the minimum energy configuration of the isolated molecule (simulated using Lorentzian functions with FWHM of 10 and $5 \mathrm{~cm}^{-1}$, respectively; for the used method to convert the Raman activities extracted from the Gaussian 09 output to the Raman intensities, see ${ }^{[45-47]}$ Raman intensities were normalized to unity intensity of the band at $1403 \mathrm{~cm}^{-1}$ ); middle panels: experimental ATR and Raman spectra of the compound.

within the range of $\mathrm{Cu}^{\text {Il }}$ concentrations found in neoplasms. In this sense, MTSB appears to be most effective towards hepatic, neuroblastoma and lymphoma, for which the least combination of $\mathrm{Cu}^{\prime \prime}$ and MTSB concentrations can be used to obtain a $50 \%$ reduction in cell viability after $72 \mathrm{~h}$ of exposure. For the monocytic leukemia THP-1, a $50 \%$ reduction in cell viability would require a $119 \mu \mathrm{M}$ concentration of MTSB.

For the non-tumor-derived cell line $\mathrm{S} 17$ a $50 \%$ reduction in cell viability is achieved with concentrations of MTSB and Cu" of 75.1 and 38.5, respectively. However, it is worth noting that, in non-tumor tissues, the normal concentration of $\mathrm{Cu}^{\text {Il }}$ were found to be less than $10 \mu \mathrm{M}$. Thus, we can argue that MTSB is toxic towards a range of cancer cells at concentrations that do not affect normal cells.

\section{Conclusion}

In the present study, the synthesis and the detailed structural characterization of MTSB were addressed. In addition, the photochemical stability of the matrix-isolated compound has been investigated. The relevant regions of the potential energy surface of the molecule were scrutinised and a detailed charge density analysis of the identified most stable conformation performed based on the AIM theory and Wiberg's bond order methods. The structural relevance of the intramolecular N...S interaction in MTSB was stressed. In situ matrix UV-irradiation revealed a high photostability of MTSB, compared to parent tetrazole saccharinates and to the 5-methyl-1,3,4-thiadiazole building block, emphasizing the photostabilizing effect of the saccharyl system.

The infrared spectrum of matrix-isolated (argon matrix) MTSB was recorded and interpreted taking into account results obtained using quantum chemical calculations at the B3LYP/6$311++\mathrm{G}(3 \mathrm{df}, 3 \mathrm{pd})$ level of approximation.

The crystal structure of the compound was also investigated by X-ray crystallography and infrared and Raman spectroscopies. It was concluded that in the crystal the molecules of MTSB assume a conformation similar to that predicted theoretically to be the most stable one for the isolated molecule situation, which was also proved to be the one present in the argon matrix. The S...N interation was also found to play a relevant role to the structure of the molecule in the crystal.

Finally, the toxicity of MTSB was evaluated in vitro, towards 6 cancer cell lines and non-tumoral cells. The results showed that MTSB is toxic towards cancer cells at concentrations that do not affect normal cells, the compound being particularly effective towards the hepatic (HepG2), neuroblastoma (SH-SY5) and lymphoma cell lines (U937).

\section{Experimental Section}

Chemicals and routine analytical equipment; general information

All chemicals (analytical grade) were used as purchased from commercial sources. When required, solvents (technical grade) were freshly distilled from appropriate drying agents before use.

Melting points were recorded on a Stuart Scientific SMP3 melting point apparatus and are uncorrected. Mass spectra were obtained on a VG 7070E mass spectrometer by electron ionization (EI) at $70 \mathrm{eV}$. NMR spectra were obtained on a Bruker AM-400 spectrometer, using TMS as the internal reference ( $\delta=0.0 \mathrm{ppm})$.

\section{Synthesis of ligands}

Preparation of 3-chloro-1,2-benzisothiazole-1,1-dioxide (2): Saccharyl chloride 2 was obtained from saccharin $(10.2 \mathrm{~g} ; 56 \mathrm{mmol})$ and phosphorus pentachloride $(14.0 \mathrm{~g} ; 66 \mathrm{mmol})$, heated at $180^{\circ} \mathrm{C}$, using a procedure reported previously: $:^{[17]}$ colorless needles $(7.00 \mathrm{~g}$; $63 \%$ yield); m.p. $143-145^{\circ} \mathrm{C}$; IR $\left(\mathrm{KBr}^{\mathrm{cm}} \mathrm{cm}^{-1}\right): \tilde{v}=1724,1654,1603$ $(\mathrm{C}=\mathrm{C}), \quad 1346 \quad\left(\mathrm{SO}_{2}\right), 775(\mathrm{Ar}-\mathrm{H})$ and $692 \mathrm{~cm}^{-1} \quad(\mathrm{C}-\mathrm{Cl}) ;{ }^{1} \mathrm{H}$ NMR $\left(400 \mathrm{MHz}, \mathrm{CDCl}_{3}\right): \delta=7.85$ ppm (m, 4H); MS (EI): $\mathrm{m} / \mathrm{z} 201[\mathrm{M}]^{+}$.

Preparation of 3-[(5-methyl-1,3,4-thiadiazol-2-yl)sulfanyl]-1,2-benzothiazole 1,1-dioxide (MTSB): A mixture of anhydrous 5-methyl-1,3,4- 
thiadiazole-2-thiol (4) $(0.65 \mathrm{~g} ; 4.92 \mathrm{mmol})$ and 3-chloro-1,2-benzisothiazole 1,1-dioxide (2) $(1.0 \mathrm{~g}, 4.97 \mathrm{mmol})$ in dry THF $(40 \mathrm{~mL})$ was stirred at $60^{\circ} \mathrm{C}$, under a nitrogen atmosphere. The reaction was monitored by TLC (ethyl acetate/hexane; $4: 6$ ). After $24 \mathrm{~h}$, the solvent was evaporated under reduced pressure and the remaining solid was dried under vacuum at room temperature. Crystallization from acetone/THF (2:1) yielded the required product as yellow crystals $\left(1.0 \mathrm{~g} ; 60 \%\right.$ yield); m.p. $190-192^{\circ} \mathrm{C} .{ }^{1} \mathrm{H} \mathrm{NMR}(400 \mathrm{MHz}$, $\left.\mathrm{CDCl}_{3}\right): \delta=8.04-7.99(\mathrm{~m}, 2 \mathrm{H}), 7.95-7.86(\mathrm{~m}, 2 \mathrm{H}), 2.79 \mathrm{ppm}(\mathrm{s}, 3 \mathrm{H})$; MS (EI): $m / z 298[M]^{+}$.

\section{Matrix experiments}

The cryogenic matrices were prepared by sublimation of the compound, using a homemade mini-oven $\left(T \approx 120^{\circ} \mathrm{C}\right)$ placed within the vacuum chamber of the cryostat, and mixing the resulting vapors with argon $\mathrm{N} 60$ in an approximate 1:1000 solute/matrix molar ratio.

The infrared spectra were recorded in a Thermo Nicolet 6700 Fourier transform infrared (FTIR) spectrometer (resolution $0.5 \mathrm{~cm}^{-1}$ ), equipped with a $\mathrm{Ge} / \mathrm{KBr}$ beam splitter and a deuterated triglycine sulfate (DTGS) detector.

UV irradiations were performed in situ, through an outer quartz window (cut-off $\approx 200 \mathrm{~nm}$ ) of the cryostat, with broadband UV light produced by a $500 \mathrm{~W} \mathrm{Hg}(\mathrm{Xe})$ lamp (Newport, Oriel Instruments) set up to provide an output of $200 \mathrm{~W}$ at the sample. During the performed irradiation experiments, the $\mathrm{Hg}(\mathrm{Xe})$ lamp was fitted with a water filter $(8 \mathrm{~cm}$ long) to absorb heat.

\section{X-ray crystallography}

Single crystal X-ray diffraction (XRD) data were collected on a Bruker APEXII CCD diffractometer using graphite monochromatized Mo K $\alpha$ radiation $(\lambda=0.71073 \AA$ ). The data collection was performed at 120 (2) K using a cooled nitrogen-gas stream in laminar flow. The single-crystal specimen was plate-shaped with dimensions $0.33 \times$ $0.13 \times 0.07 \mathrm{~mm}^{3}$. A monoclinic unit cell $(a=8.3068(6), b=9.3966(7)$, $\left.c=15.6916(11) \AA, \beta=104.065(3)^{\circ}\right)$, was first derived from indexing the Bragg spots of the first 36 CCD frames and it was further refined by least-squares from the positions of 5825 measured Bragg spots at the end of the data-collection. Systematic absences pointed to the monoclinic $P 2_{1} / c$ space-group, and this assignment was confirmed from the structure solution. Data reduction and a multiscan absorption correction were performed with the SAINT and SADABS ${ }^{[48]}$ suite of programs. The crystallographic structure was solved by direct methods using SHELXT-2014/5. ${ }^{[49]}$ Refinements using spherical atomic scattering factors were carried out with the SHELXL-2016/6 package..$^{[50]}$ All refinements were made by fullmatrix least-squares on $F^{2}$ with anisotropic displacement parameters for all non-hydrogen atoms. Hydrogen atoms were placed at calculated idealized positions and refined as riding using SHELXL2016/6 default parameters. The refined structural model gave a final $R_{1}$ factor of 0.0232 for 2481 reflections of $I>2 \sigma$ and $R_{\text {all }}$ of 0.0260 for all 2726 reflections and 164 parameters. A refinement of the structural model using aspherical scattering factors, based on a Hansen-Coppens multipole expansion formalism ${ }^{[51]}$ were carried out with XD2006. ${ }^{[52]}$ Slater-type radial functions were used. All non hydrogen atoms were refined with an expansion up to $I=3$ (octupoles), the hydrogen atoms were refined up to dipoles $(I=1)$. A set of $k$ contraction-expansion parameters for each atomic species, multipole population parameters, and anisotropic displacement parameters (isotropic for $\mathrm{H}$ atoms) were refined. A charge neutrality constraint was imposed and apropriate restrictions on the multipole parameters for an assumed $C_{\mathrm{s}}$ symmetry of the electron densi- ty of the aromatic rings. In addition, atoms with equivalent chemical environments were assumed to have the same deformation electron density. The multipole and radial $k$ parameters of non- $\mathrm{H}$ atoms were refined using 2481 reflections with $I>2 \sigma$, giving a $R_{1}$ factor of 0.0124 and $R_{\text {all }}$ of 0.0163 for all 2726 reflections and 406 parameters.

CCDC 1536536 contain the supplementary crystallographic data for this paper. These data are provided free of charge by The Cambridge Crystallographic Data Centre

\section{IR and Raman spectroscopy of crystalline MTSB}

ATR infrared spectra were collected with $2 \mathrm{~cm}^{-1}$ spectral resolution (126 scans), in a ThermoNicolet IR300 FTIR spectrometer, equipped with a Smart Orbit ATR accessory, a DTGS detector and a $\mathrm{Ge} / \mathrm{KBr}$ beam splitter.

Raman spectra were obtained using a Horiba LabRam HR Evolution micro-Raman system, with excitation at $632.8 \mathrm{~nm}$ from a He-Ne laser, spectral resolution $4.0 \mathrm{~cm}^{-1}, 50 \times$ magnification objective, acquisition time of $60 \mathrm{~s}, 10$ accumulations, and laser power $\approx 17 \mathrm{~mW}$. Calibration was done using the Si wafer band. The wavenumber accuracy is better than $0.5 \mathrm{~cm}^{-1}$ in the spectral region of interest. In all cases, the automatic focusing option was used. The Raman temperature variation studies $\left(0.1^{\circ} \mathrm{C}\right.$ resolution) were undertaken by coupling a Linkam THMS600/720 stage (controlled by a PE95/ T95 system controller) with the Raman spectrometer.

\section{Cell viability assays}

Cell viability was determined against four cell lines of adherent tumors: human hepatocellular carcinoma cell line (HepG2), human epitheloid cervix carcinoma (HeLa), human neuroblastoma cell line (SH-SY5Y) and mouse microglia cell line (N9); and two cell lines of non-adherent tumors: human monocytic leukaemia (THP-1) and human histiocytic lymphoma (U937). The non-tumoral cell line of mouse bone marrow stroma (S17) was used to assess the selectivity of the compound towards tumoral cells.

Exponentially growing S17, HepG2 and HeLa cells were plated in 96-well tissue plates at a density of $5 \times 10^{3}$ cells/well whereas $\mathrm{SH}$ SY5Y, N9, THP-1 and U937 were seeded at a density of $10 \times 10^{3}$ cells/well. All the plates were incubated for $24 \mathrm{~h}$. Compounds were then applied at various concentrations $(0-250 \mu \mathrm{M})$ for $72 \mathrm{~h}$. Control cells were treated with DMSO at the highest concentration used in test wells $(0.5 \%)$ plus copper solution at $50 \mu \mathrm{M}$, and cell viability was determined by the MTT colorimetric assay. ${ }^{[53]}$ Briefly, 2 hours prior to the end of the incubation period $20 \mu \mathrm{L}$ of $\mathrm{MTT}\left(5 \mathrm{mg} \mathrm{mL}^{-1}\right.$ in PBS) were added to each well and further incubated at $37^{\circ} \mathrm{C}$. Then, $150 \mu \mathrm{L}$ of DMSO was added to each well in order to dissolve the formazan crystals and absorbance was measured at $590 \mathrm{~nm}$ (Biotek Synergy 4).

For the evaluation of the copper concentration effect on MTSB cytotoxicity, cells were treated with the MTSB at the concentrations correspoding to its $\mathrm{IC}_{50}$ (previously determined) and copper(II) at various concentrations $(0-200 \mu \mathrm{M})$. Results were expressed in terms of $I C_{50}(\mu \mathrm{M})$. All experiments were run in triplicate.

$\mathrm{IC}_{50}$ values were calculated by sigmoidal fitting of the data in the GraphPad Prism V 5.0 program (GraphPad Software, La Jolla, CA, USA). 


\section{Acknowledgements}

This investigation has been performed within the Projects PTDC/QEQ-QFI/3284/2014-POCI-01-0145-FEDER-016617 and PTDC/MAR-BIO/4132/2014, funded by the Portuguese "Fundação para a Ciência e a Tecnologia" (FCT) and FEDER/COMPETE 2020-EU. CCMAR in supported by FCT, through the project UID/Multi/04326/2013. The Coimbra Chemistry Centre (CQC) and the Coimbra Physics Centre are supported by FCT, through the projects UI0313/QUI/2013 and UID/FIS/04564/2016, respectively, also co-funded by FEDER/COMPETE 2020-EU.

\section{Conflict of interest}

The authors declare no conflict of interest.

Keywords: cu(ii)-dependent cytotoxicity - photostability saccharinate-based copper chelators · selectivity • structural studies · thiadiazol-saccharin sulphanyl-bridged ligands

[1] G. Aromí, L. A. Barrios, O. Roubeau, P. Gamez, Coord. Chem. Rev. 2011, 255, 485-546.

[2] H. Zhao, Z.-R. Qu, H.-Y. Ye, R.-G. Xiong, Chem. Soc. Rev. 2008, 37, 84100.

[3] E. J. Baran, V. T. Yilmaz, Coord. Chem. Rev. 2006, 250, 1980-1999.

[4] J. M. Fisher, R. J. Potter, C. F. J. Barnard, Platinum Met. Rev. 2004, 48, $101-104$.

[5] A. Ruggiero, G. Trombatore, S. Triarico, R. Arena, P. Ferrara, M. Scalzone, F. Pierri, R. Riccardi, Anticancer. Drugs 2013, 24, 1007-1019.

[6] A. Gupte, R. J. Mumper, Cancer Treat. Rev. 2009, 35, 32-46.

[7] K. Jomova, M. Valko, Toxicology 2011, 283, 65-87.

[8] M. Valko, H. Morris, M. Cronin, Curr. Med. Chem. 2005, 12, 1161-1208.

[9] M. Valko, C. J. Rhodes, J. Moncol, M. Izakovic, M. Mazur, Chem.-Biol. Interact. 2006, 160, 1-40.

[10] M. Nagai, N. H. Vo, L. S. Ogawa, D. Chimmanamada, T. Inoue, J. Chu, B. C. Beaudette-Zlatanova, R. Lu, R. K. Blackman, J. Barsoum, K. Koya, Y. Wada, Free Radical Biol. Med. 2012, 52, 2142-2150.

[11] L. Duarte, I. Reva, M. L. S. Cristiano, R. Fausto, J. Org. Chem. 2013, 78, $3271-3275$.

[12] E. J. Baran, V. T. Yilmaz, Coord. Chem. Rev. 2016, 250, 1980-1999.

[13] A. Gómez-Zavaglia, A. Ismael, L. I. L. Cabral, A. Kaczor, J. A. Paixão, R. Fausto, M. L. S. Cristiano, J. Mol. Struct. 2011, 1003, 103-110.

[14] A. Ismael, A. Borba, L. Duarte, B. M. Giuliano, A. Gómez-Zavaglia, M. L. S. Cristiano, J. Mol. Struct. 2012, 1025, 105-116.

[15] L. M. T. Frija, R. Fausto, R. M. S. Loureiro, M. L. S. Cristiano, J. Mol. Catal. A 2009, 305, $142-146$.

[16] A. Ismael, M. S. C. Henriques, C. Marques, M. Rodrigues, L. Barreira, J. A. Paixão, R. Fausto, M. L. S. Cristiano, RSC Adv. 2016, 6, 71628-71637.

[17] L. M. T. Frija, M. L. S. Cristiano, A. Gómez-Zavaglia, I. Reva, R. Fausto, J. Photochem. Photobiol. C 2014, 18, 71-96.

[18] L. M. T. Frija, A. Ismael, M. L. S. Cristiano, Molecules 2010, 15, $3757-$ 3774.

[19] L. M. T. Frija, A. J. L. Pombeiro, M. N. Kopylovich, Coord. Chem. Rev. 2016, $308,32-55$

[20] Gaussian 09, Revision D.01, M. J. Frisch, G. W. Trucks, H. B. Schlegel, G. E. Scuseria, M. A. Robb, J. R. Cheeseman, G. Scalmani, V. Barone, B. Mennucci, G. A. Petersson, H. Nakatsuji, M. Caricato, X. Li, H. P. Hratchian, A. F. Izmaylov, J. Bloino, G. Zheng, J. L. Sonnenberg, M. Hada, M. Ehara, K. Toyota, R. Fukuda, J. Hasegawa, M. Ishida, T. Nakajima, Y. Honda, O Kitao, H. Nakai, T. Vreven, J. A. Montgomery, Jr., J. E. Peralta, F. Ogliaro, M. Bearpark, J. J. Heyd, E. Brothers, K. N. Kudin, V. N. Staroverov, R. Kobayashi, J. Normand, K. Raghavachari, A. Rendell, J. C. Burant, S. S. Iyen- gar, J. Tomasi, M. Cossi, N. Rega, J. M. Millam, M. Klene, J. E. Knox, J. B. Cross, V. Bakken, C. Adamo, J. Jaramillo, R. Gomperts, R. E. Stratmann, O. Yazyev, A. J. Austin, R. Cammi, C. Pomelli, J. W. Ochterski, R. L. Martin, K. Morokuma, V. G. Zakrzewski, G. A. Voth, P. Salvador, J. J. Dannenberg, S. Dapprich, A. D. Daniels, Ö. Farkas, J. B. Foresman, J. V. Ortiz, J. Cioslowski, D. J. Fox, Gaussian, Inc.: Wallingford, CT, 2009.

[21] A. D. Becke, Phys. Rev. A 1988, 38, 3098-3100.

[22] C. T. Lee, W. T. Yang, R. G. Parr, Phys. Rev. B 1988, 37, 785-789.

[23] A. D. McLean, G. S. Chandler, J. Chem. Phys. 1980, 72, 5639-5648.

[24] K. Raghavachari, J. S. Binkley, R. Seeger, J. A. Pople, J. Chem. Phys. 1980, $72,650-654$.

[25] R. F. W. Bader, Atoms in Molecules: A Quantum Theory; International Series of Monographs on Chemistry, Vol.22, Oxford University Press, Oxford, 1990.

[26] O. V. Sizova, L. V. Skripnikov, A. Yu Sokolov, J. Mol. Struct. 2008, 870, 1 9.

[27] K. B. Wiberg, Tetrahedron 1968, 24, 1083-1096.

[28] T. Lu, F. Chen, J. Comput. Chem. 2012, 33, 580-592.

[29] R. Fausto, J. J. C. Teixeira-Dias, P. R. Carey, J. Am. Chem. Soc. 1991, 113, $2471-2476$.

[30] C. P. Huber, Y. Ozaki, D. H. Pliura, A. C. Storer, P. R. Carey, Biochemistry 1982, 21, 3109-3115.

[31] K. I. Varughese, A. C. Storer, P. R. Carey, J. Am. Chem. Soc. 1984, 106, $8252-8257$.

[32] C. P. Huber, P. R. Carey, S. C. Hsi, H. Lee, A. C. Storer, J. Am. Chem. Soc 1984, 106, 8263-8268.

[33] R. E. Rosenfield, R. Parthasarathy, J. D. Dunitz, J. Am. Chem. Soc. 1977, 99, 4860-4862.

[34] A. Bauzá, T. J. Mooibroek, A. Frontera, ChemPhysChem 2015, 16, 2496 2517.

[35] O. Gálvez, P. C. Gómez, L. F. Pacios, J. Chem. Phys. 2001, 115, 1116611184.

[36] E. Espinosa, I. Alkorta, J. Elguero, E. Molins, J. Chem. Phys. 2002, 117, 5529-5542.

[37] R. Vessecchi, J. N. C. Lopes, N. P. Lopes, S. E. Galembeck, J. Phys. Chem. A 2011, 115, $12780-12788$.

[38] B. Sirjean, P. A. Glaude, M. F. Ruiz-Lopez, R. Fournet, J. Phys. Chem. A 2008, 112, 11598- 11610.

[39] H. M. Muchall, ARKIVOC (Gainesville, FL, U.S.) 2001, 12, 82-86.

[40] J. Bacsa, J. Briones, Acta Crystallogr. Sect. C 2013, 69, 910-914.

[41] A. Kaczor, R. Almeida, A. Gómez-Zavaglia, M. L. S. Cristiano, R. Fausto, J. Mol. Struct. 2008, 876, 77-85.

[42] A. Borba, A. Gómez-Zavaglia, R. Fausto, J. Phys. Chem. A 2013, 117, $704-717$.

[43] H. Rostkowska, L. Lapinski, M. J. Nowak, J. Phys. Org. Chem. 2010, 23, $56-66$.

[44] A. L. Ismael, Ph.D. Thesis, Department of Chemistry and Pharmacy, University of Algarve (Portugal), 2017.

[45] P. L. Polavarapu, J. Phys. Chem. 1990, 94, 8106-8112.

[46] V. Krishnakumar, G. Keresztury, T. Sundius, R. Ramasamy, J. Mol. Struct. 2004, 702, 9-21.

[47] D. Michalska, R. Wysokinski, Chem. Phys. Lett. 2005, 403, 211-217.

[48] Bruker, APEX2. In SAINT and SADABS; Bruker AXS Inc.: Madison, WI, USA, 2014

[49] G. M. Sheldrick, SHELXT, Acta Crystallogr. Sect. A 2015, 71, 3-8.

[50] G. M. Sheldrick, SHELXL, Acta Crystallogr. Sect. C 2015, 71, 3-8.

[51] N. K. Hansen, P. Coppens, Acta Crystallogr. Sect. A 1978, 34, 909-921.

[52] A. Volkov, P. Macchi, L. J. Farrugia, C. Gatti, P. Mallinson, T. Richter, T. Koritsanszky, XD2006-A Computer Program Package for Multipole Refinement, Topological Analysis of Charge Densities and Evaluation of Intermolecular Energies from Experimental and Theoretical Structure Factors, 2006

[53] T. Mosmann, J. Immunol. Methods 1983, 65, 55-63.

Manuscript received: November 9, 2017

Accepted manuscript online: December 28, 2017

Version of record online: February 5, 2018 